\title{
Plasma cyclic AMP levels during a secretin- caerulein pancreatic function test in liver and pancreatic disease
}

\author{
M. ADleR, P. ROBbERECHT, M. G. POITEVIN, AND J. CHRISTOPHE 1 \\ From the Department of Biochemistry and Nutrition, Free University of Brussels Medical School; and \\ Department of Gastroenterology, Hospital of Ixelles, Brussels, Belgium
}

SUMMARY Plasma cyclic AMP levels were determined during a 40 minute secretin infusion $(1 \mathrm{Cl} . \mathrm{U}$ $\left.\mathrm{kg}^{-1} \mathrm{~h}^{-1}\right)$ followed by a 40 minute combined secretin $\left(1 \mathrm{Cl} . \mathrm{U} \mathrm{kg}^{-1} \mathrm{~h}^{-1}\right)$ caerulein $\left(75 \mathrm{ng} \mathrm{kg}^{-1} \mathrm{~h}^{-1}\right)$ infusion. In nine healthy subjects, both secretin alone and secretin in combination with caerulein did not affect plasma cyclic AMP levels. The same was observed in six patients with chronic pancreatitis. By contrast, in patients suffering from liver disease (nine cases) or extrahepatic cholestasis (six cases), secretin elicited large increases in plasma cyclic AMP concentration; the mean values attained being, respectively, seven and four times higher than before the infusion. On the other hand, increases in plasma cyclic AMP 10 minutes after a bolus injection of glucagon $(1 \mathrm{mg})$ were four times lower in the liver disease group as compared to the controls. The results reported here suggest that the liver plays a major role in the degradation of plasma cyclic AMP produced by target tissues responding to secretin, and in the release of cyclic AMP under glucagon. Liver disease reduce the capacity of the liver to clear cyclic AMP from the blood. The pancreas does not contribute significantly to the cyclic AMP in the blood.

Secretin and caerulein (a cholecystokinin-pancreozymin analogue) are commonly used in pancreatic function tests.

Adenosine $3^{\prime}: 5^{\prime}$-cyclic monophosphate may play the role of intracellular messenger of secretin and two structurally related hormones, vasoactive intestinal polypeptide and glucagon, for the pancreatic secretion of water and bicarbonate, gastrointestinal secretion and motility, liver metabolism, and biliary secretion (Levine, 1970; Kimberg, 1974).

As the release of cyclic AMP to extracellular compartments and blood is proportional to intracellular concentrations (Taylor et al., 1970; Williams et al., 1972), it is reasonable to expect that variations in

Abbreviations Cyclic AMP: adenosine $3^{\prime}: 5^{\prime}$-cyclic monophosphoric acid; cyclic GMP: guanosine $3^{\prime}: 5^{\prime}$-cyclic monophosphoric acid.

${ }^{1}$ Address for correspondence: Dr Jean Christophe, Department of Biochemistry and Nutrition, Free University of Brussels Medical School, Boulevard de Waterloo 115, B-1000 Brussels, Belgium

Received for publication 24 October 1977 plasma cyclic AMP may reflect the response of target tissues to hormone administration.

The control of the exocrine pancreas by cholecystokinin-pancreozymin and by an analogue such as caerulein is probably different and includes transient rises in calcium efflux and guanosine $3^{\prime}: 5^{\prime}$-cyclic monophosphate levels. Data supporting this mechanism have been documented in rat and guineapig (Robberecht, 1976; Christophe et al., 1976) but has not yet been investigated in man.

The initial purpose of the present study was to explore the possible usefulness of plasma cyclic AMP determinations during secretin and caerulein infusions as a further pancreatic function test. It became evident, however, that the data obtained were more useful in evaluating hepatic rather than pancreatic impairments.

\section{Methods}

\section{SUBJECTS}

Thirty-one adult patients were studied ( 21 males and 10 females). They were referred to the hospital for a 
suspected or demonstrated gastrointestinal disease and were all submitted to complete pancreatic and hepatic investigation. Pancreatic investigation included plain radiographs of the abdomen (anteroposterior and right and left oblique projections), blood amylase determination, and the functional test described below. Hepatobiliary evaluation included radiological examination (plain radiographs of abdomen and per os or intravenous cholangiography), the measurement of transaminases, alkaline phosphatase, 5'nucleotidase, and $\gamma$ glutamyl transpeptidase in the blood, blood protein electrophoresis, and a 45 minute bromsulphalein (BSP) determination. In addition, a laparoscopy was performed in nine cases, hepatic histology was obtained in seven cases via the laparoscope, and surgical diagnosis was made in seven other cases.

According to the diagnosis, the patients were subdivided into five groups:

\section{Healthy subjects with no evidence of}

hepatopancreatic disease or proven organic disease of the gastrointestinal tract

There were nine subjects in this group.

\section{Patients with chronic pancreatitis}

Of the six patients in this group three were alcoholic and three idiopathic. The secretin-caerulein function test was abnormal in each subject; in two of them pancreatic calcifications were observed on the radiographs and in two others an operation confirmed the diagnosis.

\section{Patient with total pancreatectomy performed for non-metastatic cancer of head of pancreas}

In this patient, investigated six months after the operation, no duodenal juice was collected during the secretin-caerulein test.

\section{Patients with chronic liver disease}

Of these nine patients eight had a history of heavy alcoholism. Alcoholic liver disease was demonstrated histologically in seven of these cases; a decompensated cirrhosis with ascites was present in one case; the last patient underwent a portacaval anastomosis for post-hepatitic cirrhosis. Among the seven patients with demonstrated alcoholic liver disease, alcoholic hepatitis was manifest in three, fat and fibrosis with pending cirrhosis in two, and cirrhosis in two. In these seven cases, $\gamma$ glutamyl transpeptidase activity was considerably raised (at least five-fold increases over the average control value), and jaundice was present in the three patients with alcoholic hepatitis. In addition, at least one and usually all the following tests were abnormal: transaminases, alkaline phosphatase, and/or BSP.

\section{Patients with extrahepatic cholestasis}

In two of the six patients in this group the condition was due to biliary carcinoma, stones in the common bile duct (two cases), and obstructive chronic pancreatitis with stenosis of the common bile duct (two).

\section{TECHNIQUES}

\section{Secretin-caerulein test}

The pancreatic function test has been described in a previous study (Van der Hoeden et al., 1971). In short, after an overnight fast, a double-lumen tube was introduced to allow separate collection of duodenal and gastric secretions. Natural secretin was infused at the constant rate of $1 \mathrm{Cl} . \mathrm{U} \mathrm{kg}^{-1} \mathrm{~h}^{-1}$ during 80 minutes, and caerulein $\left(75 \mathrm{ng} \mathrm{kg}^{-1} \mathrm{~h}^{-1}\right.$ ) was infused in addition to secretin after $\mathbf{4 0}$ minutes of secretin only. The duodenal juice was collected over ice by continuous aspiration and fractionated into eight successive 10-minute samples. Bicarbonate and amylase were assayed on each fraction. As previously established (Van der Hoeden et al., 1971), the most useful determinations for the diagnosis were the bicarbonate output (in $\mathrm{mmol} / 10 \mathrm{~min}$ ) in the fourth duodenal aspirate (30-40 minutes after the beginning of the secretin infusion) and amylase output (in $\mathrm{U} / 10 \mathrm{~min}$ ) in the sixth sample (50-60 minutes) -that is, during the second 10 minute period of the combined secretin-caerulein perfusion. Bicarbonate was determined by the gasometric method of Van Slyke and amylase activity was measured according to Van Loon's iodometric technique (Van Loon et al., 1952). Both methods were automated.

In parallel with the collection of duodenal juice, blood samples were withdrawn immediately before the test, and every 10 minutes during the secretin and the secretin plus caerulein infusions, for plasma cyclic AMP determinations (see below).

\section{Glucagon test}

In 12 subjects (seven of the control group and five of the liver disease group) plasma cyclic AMP and blood glucose were determined after a bolus intravenous injection of glucagon $(1 \mathrm{mg})$. Both determinations were made immediately before, and 10 and 20 minutes after the hormone injection. This rapid test was conducted one or two days after the somewhat more cumbersome secretin-caerulein test.

\section{Plasma cyclic AMP determination}

Blood samples were collected in EDTA-coated tubes and immediately centrifuged. The plasma was stored at $-20^{\circ} \mathrm{C}$ until analysed. Cyclic AMP was determined by the protein binding assay of Tovey et al. (1974), which does not require preliminary purification. Accurate determinations of 0.4 picomol 
cyclic AMP could be performed using muscle bovine protein kinase according to Gilman (1970). Plasma cyclic AMP determinations were made in duplicate on appropriate plasma dilutions; variations between duplicate values were around $5 \%$.

\section{CHEMICALS}

Natural porcine secretin was obtained from the GIH Research Unit of the Karolinska Institutet (Stockholm, Sweden). Synthetic caerulein and pure crystalline porcine glucagon were generous gifts from Farmitalia-Montedison (Benelux, Brussels, Belgium) and Novo Industri (A. Couvreur, Brussels, Belgium) respectively. All reagents were commercial preparations of analytical grade, including cyclic AMP (Sigma Co., St. Louis, Mo., USA), Charcoal Norit SG extra (Baker Chemical Co., Phillisburg, N.J., USA), and $8-\left[{ }^{3} \mathrm{H}\right]$ cyclic AMP with a specific radioactivity of $27 \mathrm{Ci} / \mathrm{mmol}$ (Radiochemical Centre, Amersham, England).

\section{STATISTICAL ANALYSIS}

Student's paired and unpaired $t$ tests were used to evaluate the statistical significance of the results obtained. Mean values \pm SEM are given in the text.

\section{Results}

PANCREATIC FUNCTION TEST

A summary of individual results is presented in Fig. 1 with the two most significant parameters-namely, maximal bicarbonate output (in $\mathrm{mmol} / 10 \mathrm{~min}$ ) under secretin alone (at time 30-40 minutes) and maximal amylase output (in $\mathrm{U} / 10 \mathrm{~min}$ ) observed at time 50-60 minutes during the second 10 minute period of the combined infusion of caerulein and secretin.

In healthy subjects, a maximal bicarbonate output of $4.0 \pm 0.7 \mathrm{mmol} / 10 \mathrm{~min}$ (mean \pm SEM) and a maximal amylase output of $48170 \pm 9130 \mathrm{U} / 10$ min (mean \pm SEM) were obtained. A marked decrease in both bicarbonate $(2.1 \pm 0.5 \mathrm{mmol} / 10$ min, $P<0.05)$ and amylase output $(7870 \pm 3880, P$ $<0.05)$ was observed in chronic pancreatitis. Extrahepatic cholestasis produced similar decreases in bicarbonate $(2.1 \pm 0.4 \mathrm{mmol} / 10 \mathrm{~min}, \mathrm{P}<0.05)$ and amylase output $(5540 \pm 1660 \mathrm{U} / 10 \mathrm{~min}, \mathrm{P}<0.05)$, which suggests that extrahepatic cholestasis was associated with impaired pancreatic function. In the liver diseases group, bicarbonate output was normal $(5.5 \pm 1.1 \mathrm{mmol} / 10 \mathrm{~min})$ whereas amylase output was decreased $(13470 \pm 5800 \mathrm{U} / 10 \mathrm{~min}, \mathrm{P}<0.05)$. The existence of normal bicarbonate output in the face of decreased amylase output can be tentatively interpreted as an increased choleretic response to secretin (Dreiling and Bordalo, 1973; Wettendorff

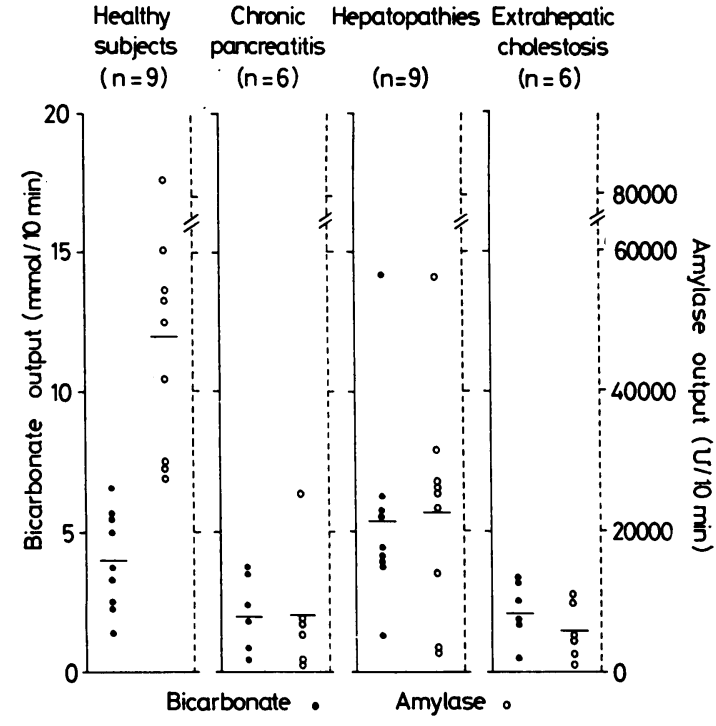

Fig. 1 Pancreatic function tests in nine healthy subjects, six patients with chronic pancreatitis, nine patients suffering from hepatopathies, and six patients presenting extrahepatic cholestasis. The protocol is detailed in the Methods section. In each panel, bicarbonate output (to the left) is the value (in mmol/10 min) determined in the duodenal juice collected 30 to 40 minutes after the beginning of the secretin infusion. Amylase output (in U/10 min) was assayed in the duodenal juice collected during the period 50-60 minutes -that is, 10 to 20 minutes after the beginning of the combined caerulein-secretin infusion. The horizontal bar represents the mean of the values obtained in each group.

et al., 1974) associated with impaired pancreatic function.

EFFECT OF SECRETIN AND CAERULEIN ON PLASMA CYCLIC AMP LEVELS

Mean fasting plasma cyclic AMP levels (mean \pm $\mathrm{SEM}$, in $\mathrm{nmol} / \mathrm{l}$ ) were $6.6 \pm 1.3$ in healthy subjects, $7 \cdot 4 \pm 1 \cdot 1$-that is, not significantly different from healthy subjects-in patients with chronic pancreatitis, $13.1 \pm 1.9(P<0.01)$ in patients with liver disease, and 16.6 \pm 6.8 (not significantly different from healthy subjects) in patients with extrahepatic cholestasis.

Plasma cyclic AMP did not change significantly after secretin infusion in healthy subjects and in patients with chronic pancreatitis (Fig. 2). The addition of caerulein to the secretin infusion also exerted no significant effect on plasma cyclic AMP levels. In the patient who underwent total pancreatectomy, there was a moderate two-fold increase after 30-40 minutes of secretin infusion (Fig. 2). In contrast, secretin provoked a progressive and significant 


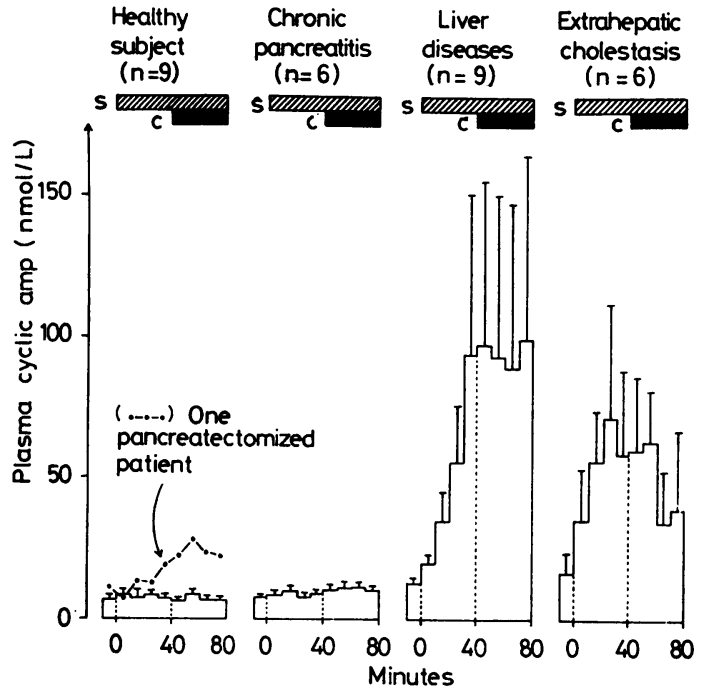

Fig. 2 Kinetics of plasma cyclic AMP levels (in picomol/ml) during a pancreatic function test, in nine healthy subjects, one totally pancreatectomized patient (- - -), six patients with chronic pancreatitis, nine patients suffering from hepatopathies, and six patients with extrahepatic cholestasis. The protocol is detailed in the Methods section and in Fig. 1. Each bar represents mean cyclic $A M P$ values $\pm S E M$.

$(P<0.05)$ rise in plasma cyclic AMP in the group with liver disease and extrahepatic cholestasis (nineand four-fold respective increases being observed, after a 30-40 minute infusion period: Fig. 2). The difference observed between these groups of patients was not significant. These rises in plasma cyclic AMP were in most cases maintained during the combined caerulein-secretin infusion (Fig. 2).

\section{EFFECT OF GLUCAGON ON PLASMA CYCLIC} AMP LEVELS AND GLYCAEMIA

In healthy subjects large increases in plasma cyclic AMP were observed in response to glucagon injection. These rises were strikingly and significantly $(P<0.05)$ reduced in patients with a liver disease, in samples taken 10 minutes after the bolus injection of glucagon (Fig. 3). In addition, the slight fasting hyperglycaemia observed in patients with liver disease did not change markedly after glucagon injection, whereas a significant increase $(P<0.01)$ in the blood glucose level developed in healthy patients.

\section{Discussion}

In healthy subjects and in patients with chronic pancreatitis, a secretin infusion, administered at a rate to provoke submaximal pancreatic stimulation
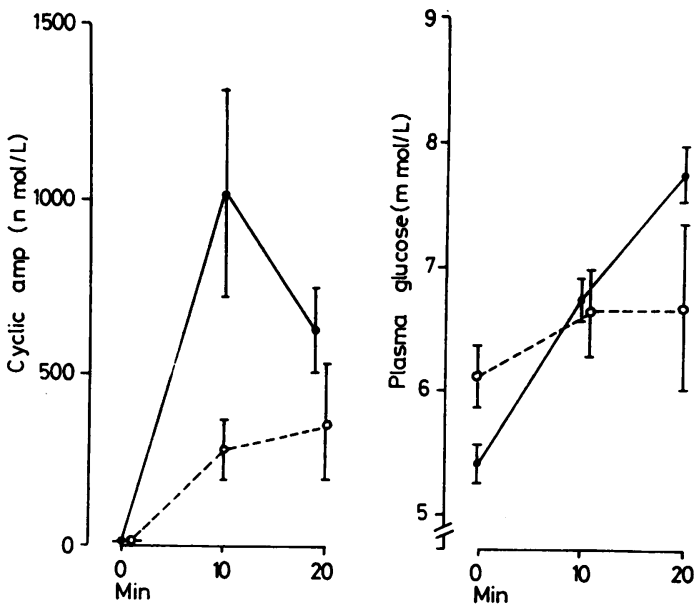

Fig.3 Glucagon tests in seven healthy subjects (-) and five patients suffering from hepatopathies (- -- ). Plasma cyclic AMP levels (in picomol/ml) and blood glucose concentration (in mmol/l), immediately before, and 10 and 20 minutes after the bolus intravenous injection of $1 \mathrm{mg}$ glucagon. Each bar represents mean values \pm SEM.

(Petersen, 1970) did not influence plasma cyclic AMP concentration (Fig. 2). In contrast, high levels of plasma cyclic AMP were attained after secretin infusion in patients with fatty liver, cirrhosis, or extrahepatic cholestasis.

Adipose tissue, the exocrine pancreas, the gut, and the liver are well known target tissues for secretin. In man, this hormone stimulates lipolysis in adipose tissue (Raptis et al., 1969), water and bicarbonate secretion by the exocrine pancreas (Wormsley, 1968), ion transport in gut (Hicks and Turnberg, 1973), and bile flow from the liver (Levine and Hall, 1976). Notably, however, an effect of secretin on hepatic glycogenolysis has not been demonstrated (Spiegel and Bitensky, 1969; Desbuquois, 1974). The action of secretin to activate a membrane adenylate cyclase in adipose tissue, pancreas, and liver is probably responsible for these effects (Rodbell et al., 1970; Desbuquois, 1974; Deschodt-Lanckman et al., 1975). The mechanism of action of secretin on the gut is generally assumed to be the same, but experimental evidence is lacking (Klaeveman et al., 1975).

The fate of cyclic AMP formed in different cells can vary. For instance, in the pancreas, a complex cyclic nucleotide phosphodiesterase system is able rapidly to hydrolyse cyclic AMP (Robberecht et al., 1974), but some cyclic AMP also diffuses into the blood (Robberecht, 1976) or escapes into the pancreatic juice (Domschke et al., 1976). A similar cyclic nucleotide disposal has been described for the liver after hormonal stimulation (Broadus et al., 1970; 
Levine and Hall, 1976). Although the diffusion of cyclic AMP to extracellular spaces is proportional to the amount of cyclic AMP formed in the tissue (Taylor et al., 1970; Williams et al., 1972), the relative importance of intracellular hydrolysis versus release is difficult to determine. In the present situation, the steady levels of plasma cyclic AMP encountered in healthy subjects, in response to secretin infusion, suggests that any added release of cyclic AMP from target organs was balanced by an appropriate rapid disposal (Gorin and Brenner, 1976).

As chronic pancreatitis did not affect plasma cyclic AMP levels after secretin infusion, either the release of cyclic AMP from the diseased gland was normal or the fibrotic lesions did not alter the response of the adenylate cyclase system to secretin. This, and the fact that cyclic AMP remained normal or supranormal (see below) in the totally pancreatectomised patient implies that the pancreas did not contribute significant amounts of cyclic AMP to the blood.

In contrast, the relatively high levels of fasting plasma cyclic AMP and the marked response to secretin infusion observed in the groups with liver pathology and extrahepatic cholestasis suggest that either increased nucleotide production or decreased catabolism of cyclic AMP may be occurring in these patients. There is no argument supporting the first hypothesis. Theoretically, of course, increased cyclic AMP levels might have been secondary to higher levels of circulating secretin. However, preliminary observations by Kolts et al. (1976) to this effect are not supported by recent radioimmunoassays of blood secretin in liver disease (Rayford et al., 1976). Increased hormone sensitivity of the adenylate cyclase system in damaged liver cells might also be postulated. The decreased effect of glucagon on blood cyclic AMP levels in liver disease does not support this hypothesis (Fig. 3). Although glucagon acts on a different liver receptor than secretin (Desbuquois et al., 1973), the present data indicate low hepatic membrane responsiveness in liver disease (Fig. 3). Thus, the high levels of cyclic AMP observed in liver disease during secretin infusion cannot be explained by increased sensitivity of the liver plasma membrane to the hormone. That glucagon-induced hyperglycaemia is altered in patients with liver disease has already been reported by Van Itallie and Bentley (1955).

The liver plays a key role in the metabolism of plasma cyclic AMP. It is involved in its production under appropriate hormonal stimulation (Williams et al., 1972). Glucagon was a much more powerful agent in this respect than secretin (Fig. 3). It is also implicated in the disposal and hydrolysis of plasma cyclic AMP (Levine et al., 1969). Indeed, plasma cyclic AMP levels decrease after a single passage through the liver, and increase in functionally hepatectomised rats (Strange and Mjøs, 1975). For these reasons we consider that the uptake and catabolism of cyclic AMP probably decreases in liver disease.

The increased levels of plasma cyclic AMP observed after secretin infusion in patients with extrahepatic cholestasis presumably reflected a reflux of the nucleotide from the liver into the blood. A similar phenomenon has already been demonstrated with glucagon as a stimulant (Francavilla et al., 1976). On this basis, it is conceivable that the moderate rise in plasma cyclic AMP in the patient who underwent total pancreatectomy was indicative of residual cholestasis.

Caerulein, an analogue of cholecystokininpancreozymin with the biological properties of the native hormone, superimposed no consistent effect on the plasma levels of cyclic AMP in normal and diseased patients. This is in agreement with our results with the perfused rat pancreas and with the model postulated for pancreozymin action in rat and guinea-pig. The hormone exerts no pronounced effects on cyclic AMP levels in the gland and in the perfusate, and appears to act mostly on calcium distribution and cyclic GMP levels (Robberecht, 1976; Christophe et al., 1976).

From these data, a hypothetical scheme emerges. During secretin administration in man, cyclic AMP diffuses from target organs such as adipose tissue, gut, pancreas, and liver. The pancreas and the liver contribute only modestly to blood cyclic AMP. However, the liver delivers more cyclic AMP after glucagon administration. In healthy subjects, the increase in blood cyclic AMP accompanying secretin infusion is overcome by nucleotide uptake by the liver, followed by hydrolysis and/or biliary excretion. Plasma cyclic AMP rose markedly when this mechanism was impaired by hepatocellular failure or extrahepatic obstruction.

The authors wish to thank Dr A. Delcourt for helpful discussion, and Dr J. C. Hutton and Mrs J. Ballinckx for editing the manuscript. This work was supported by Grant 20,403 from the Fonds de la Recherche Scientifique Médicale (Belgium) and Grant RO-1AM-17010 from the National Institutes of Health (USA).

\section{References}

Broadus, A. E., Kaminsky, N. I., Northcutt, R. C., Hardman, J. G., Sutherland, E. W., and Liddle, G. W. (1970). Effects of glucagon on adenosine $3^{\prime}, 5^{\prime}$-monophosphate and guanosine $3^{\prime}, 5^{\prime}$-monophosphate in human plasma and urine. Journal of Clinical Investigation, 49, 2237-2245.

Christophe, J. P., Frandsen, E. K., Conlon, T. P., Krishna, G., and Gardner, J. D. (1976). Action of cholecystokinin, cholinergic agents, and A-23187 on accumulation of 
guanosine $3^{\prime}: 5^{\prime}$-monophosphate in dispersed guinea-pig pancreatic acinar cells. Journal of Biological Chemistry, 251, 4640-4645.

Desbuquois, B. (1974). The interaction of vasoactive intestinal polypeptide and secretin with liver-cell membranes. European Journal of Biochemistry, 46, 439-450.

Desbuquois, B., Laudat, M. H., and Laudat, P. (1973). Vasoactive intestinal polypeptide and glucagon: stimulation of adenylate cyclase activity via distinct receptors in liver and fat cell membranes. Biochemical Biophysical Research Communications, 53, 1187-1194.

Deschodt-Lanckman, M., Robberecht, P., De Neef, P., Labrie, F., and Christophe, J. (1975). In vitro interactions of gastrointestinal hormones on cyclic adenosine $3^{\prime}: 5^{\prime}$ monophosphate levels and amylase output in the rat pancreas. Gastroenterology, 68, 318-325.

Domschke, S., Domschke, W., Rösch, W., Konturek, S. J., Wünsch, E., and Demling, L. (1976). Bicarbonate and cyclic AMP content of pure human pancreatic juice in response to graded doses of synthetic secretin. Gastroenterology, 70, 533-536.

Dreiling, D. A., and Bordalo, O. (1973). Secretory patterns in minimal pancreatic inflammatory pathologies. American Journal of Gastroenterology, 60, 60-69.

Francavilla, A., Pansini, F., Sansone, F., Di Cillo, M., and Albano, O. (1976). Test au glucagon-AMP cyclique. Médecine et Chirurgie Digestives, 5, 215-218.

Gilman, A. G. (1970). A protein binding assay for adenosine 3'-5'-cyclic monophosphate. Proceedings of the National Academy of Sciences (USA), 67, 305-312.

Gorin, E., and Brenner, T. (1976). Extracellular metabolism of cyclic AMP. Biochimica et Biophysica Acta, 451, 20-28.

Hicks, T., and Turnberg, L. A. (1973). The influence of secretin on ion transport in the human jejunum. Gut, 14, 485-490.

Kimberg, D. V. (1974). Cyclic nucleotides and their role in gastrointestinal secretion. Gastroenterology, 67, 1023-1064.

Klaeveman, H. L., Conlon, T. P., Levy, A. G., and Gardner, J. D. (1975). Effects of gastrointestinal hormones on adenylate cyclase activity in human jejunal mucosa. Gastroenterology, 68, 667-675.

Kolts, B. E., Fabri, P. J., and McGuigan, J. E. (1976). The half-life of exogenous secretin in cirrhosis (Abstract). Gastroenterology, 70, 903.

Levine, R. A. (1970). The role of cyclic AMP in hepatic and gastrointestinal function. Gastroenterology, 59, 280-300.

Levine, R. A., and Hall, R. C. (1976). Cyclic AMP in secretin choleresis. Evidence for a regulatory role in man and baboons but not in dogs. Gastroenterology, 70, 537-544.

Levine, R. A., Lewis, S. E., Shulman, J., and Washington, A. (1969). Metabolism of cyclic adenosine-3',5'-monophosphate-8 $-{ }^{14} \mathrm{C}$ by isolated, perfused rat liver. Journal of Biological Chemistry, 244, 4017-4022.

Petersen, H. (1970). The effect of pure natural secretin on the bicarbonate secretion into the duodenum in man. Scandinavian Journal of Gastroenterology, 5, 105-111.
Raptis, S., Faulhaber, J. D., and Schröder, K. E. (1969). The effect of intestinal hormones upon lipolysis of isolated human fat cells. Hormone and Metabolic Research, 1, 249. 250.

Rayford, P. L., Miller, T. A., and Thompson, J. C. (1976). Secretin, cholecystokinin and newer GI hormones (First of two parts). New England Journal of Medicine, 294, 10931101 .

Robberecht, P. (1976). The role of cyclic nucleotides in pancreatic enzyme and electrolyte secretion, in StimulusSecretion Coupling in the Gastrointestinal Tract, pp. 203226. Edited by R. M. Case and H. Goebell. MTP Press: Lancaster, England.

Robberecht, P., Deschodt-Lanckman, M., De Neef, P., and Christophe, J. (1974). Hydrolysis of the cyclic $3^{\prime}:-5^{\prime}-$ monophosphates of adenosine and guanosine by rat pancreas. European Journal of Biochemistry, 41, 585-591.

Rodbell, M., Birnbaumer, L., and Pohl, S. L. (1970). Adenyl cyclase in fat cells. III. Stimulation by secretin and the effects of trypsin on the receptors for lipolytic hormones. Journal of Biological Chemistry, 245, 718-722.

Spiegel, A. M., and Bitensky, M. W. (1969). Effects of chemical and enzymatic modifications of glucagon on its activation of hepatic adenyl cyclase. Endocrinology, 85, 638-643.

Strange, R. C., and Mjøs, O. D. (1975). The sources of plasma cyclic AMP: studies in the rat using isoprenaline, nicotinic acid and glucagon. European Journal of Clinical Investigation, 5, 147-152.

Taylor, A. L., Davis, B. B., Pawlson, G., Josimovich, J. B., and Mintz, D. H. (1970). Factors influencing the urinary excretion of $3^{\prime}, 5^{\prime}$-adenosine monophosphate in humans. Journal of Clinical Endocrinology and Metabolism, 30, 316324.

Tovey, K. C., Oldham, K. G., and Whelan, J. A. M. (1974). A simple direct assay for cyclic AMP in plasma and other biological samples using an improved competitive protein binding technique. Clinica Chimica Acta, 56, 221-234.

Van der Hoeden, R., Delcourt, A., and Algoet, P. (1971). Le test sécrétine-pancréozymine. Recherche d'un paramètre significatif. Acta Gastroenterologica Belgica, 34, 34-45.

Van Itallie, T. B., and Bentley, W. B. A. (1955). Glucagoninduced hyperglycemia as an index of liver function. Journal of Clinical Investigation, 34, 1730-1737.

Van Loon, E. J., Likins, M. R., and Seger, A. J. (1952). Photometric method for blood amylase by use of starchiodine color. American Journal of Clinical Pathology, 22, 1134-1136.

Wettendorff, P., Van der Hoeden, R., and Delcourt, A. (1974). Pancréas: réponse exagérée à la sécrétine. Acta Gastroenterologica Belgica, 37, 520-528.

Williams, R. H., Barish, J., and Ensinck, J. W. (1972). Hormone effects upon cyclic nucleotide excretion in man. Proceedings of the Society for Experimental Biology and Medicine, 139, 447-454.

Wormsley, K. G. (1968). Response to secretin in man. Gastroenterology, 54, 197-209. 